\title{
Ovulation incidence with oral contraceptives: a literature review
}

\author{
Ian Milsom, Tjeerd Korver
}

\begin{abstract}
Background and methodology Combined oral contraceptives (COCs) provide reliable and convenient contraception, although contraindications and tolerability issues may limit their use in some women. Progestogenonly pills (POPs) may be more suitable for some women, however, traditional POPs do not have the same contraceptive efficacy as COCs. A literature search was performed in order to assess the incidence of ovulation with available COCs, traditional POPs and with a desogestrel POP [Cerazette ${ }^{\circledR}, 75 \mu \mathrm{g}$ desogestrel (DSG)]. The following databases were searched: MEDLINE, EMBASE, Biosis, Derwent Drug File, Current Contents and the in-house Organon database 'Docs' (which contains all published reports of Organon products). Searches used free-text terms [e.g. Contraceptive $\$$ in combination with (Ovulat\$ adj Rate\$), (Ovar\$ adj Activ\$) or (Escap\$ adj Ovulat\$)] and were limited to the search criteria 'Human' and 'from 1979 onwards'. The searches included publications up to July 2008.
\end{abstract}

Results Many of the studies were hampered by inadequate ovulation criteria; however, the overall incidence of ovulation determined by the reports uncovered in the literature search was $2.0 \%$ [95\% confidence interval (Cl) 1.1-3.3] with COCs containing 30-35 $\mu \mathrm{g}$ ethinylestradiol (EE), 1.1\% (95\% Cl $0.60-2.0)$ with $15-20 \mu \mathrm{g}$ EE COCs, $4.6 \%(95 \% \mathrm{Cl}$ 2.8-6.9) with phasic COCs, $1.25 \%(95 \% \mathrm{Cl} 0.03-6.8)$ with Cerazette and $42.6 \%(95 \% \mathrm{Cl} 33.4-52.2)$ with traditional POPs.

Conclusions The findings indicate that COCs and the desogestrel POP are equally effective in suppressing ovulation, whilst the traditional POP formulations are less effective.

Keywords combined oral contraceptive, desogestrel, oral contraceptive, ovulation, progestogen-only pill

J Fam Plann Reprod Health Care 2008; 34(4): 237-246

(Accepted 19 August 2008)

\section{Introduction}

Oral contraceptives are the most common means of contraception in many countries and it is estimated that as many as 100 million women worldwide currently rely on this method. Approximately half of all married women in Western Europe use the oral contraceptive pill (i.e. three in every five contraceptive users) and, in the USA, they have been used by $80 \%$ of all women born since $1945.1-4$ Their widespread use warrants continuing efforts to improve and refine oral contraceptive methods.

The first oral contraceptive pill became available in 1960 and consisted of $150 \mu \mathrm{g}$ mestranol plus $9.85 \mathrm{mg}$ norethynodrel. These doses were much higher for both the estrogenic component and the progestogenic component compared to modern low-dose combined oral contraceptives (COCs). COCs provide highly reliable and convenient contraception, which is safe and well tolerated by many women. A number of side effects predominantly attributed to estrogen, such as nausea, headache, breasttenderness and bloating, can, however, make them unacceptable to some women. These problems have been addressed to some extent by lowering the doses of both estrogen and progestogen.

Estrogen-free contraception appeared in the early 1970s when the traditional progestogen-only pills (POPs) were developed in response to reports of the effects of estrogen on thromboembolic disease. As well as lacking the estrogen

Department of Obstetrics and Gynaecology, Sahlgrenska Academy at Göteborg University, Göteborg, Sweden Ian Milsom, MD, PhD, Professor

Global Clinical Development, Schering-Plough Research Institute, Oss, The Netherlands

Tjeerd Korver, PhD, Clinical Group Director Gynaecology

Correspondence to: Dr Tjeerd Korver, Global Clinical Development, Schering-Plough Research Institute, PO Box 20, $5340 \mathrm{BH}$, Oss, The Netherlands.

E-mail: tjeerd.korver@spcorp.com

\section{Key message points}

- Many contraceptive ovulation inhibition studies are hampered by inadequate methodology and/or ovulation criteria.

- Combined oral contraceptives and the desogestrel progestogen-only pill (POP) are equally effective in suppressing ovulation, and more effective than traditional POP formulations.

component, they also contain lower doses of progestogen than COCs. In contrast to COCs, which are not recommended for breastfeeding women as they can impair the quality and quantity of breast milk, ${ }^{5}$ POPs are suitable for breastfeeding women also. However, traditional POPs are also associated with a number of significant disadvantages. Most importantly, they lack the efficacy of the COCs with regard to ovulation inhibition (ovulation inhibition has been reported to occur in only approximately $50 \%$ of the treatment periods with traditional POPs). ${ }^{6}$ Contraceptive efficacy with traditional POPs places greater reliance on an increased viscosity of the cervical mucus that reduces sperm viability and penetration. ${ }^{7}$ This effect is extremely sensitive to progestogen levels in the serum. ${ }^{8}$ The efficacy of traditional POPs therefore requires strict adherence to the dosing schedule (i.e. efficacy is significantly diminished if the pill is taken more than 3 hours later than scheduled). Other effects - such as reduction in the activity of the cilia in the Fallopian tubes and changes in the endometrium that make implantation unfavourable - also play some role. ${ }^{6}$

Cerazette $^{\circledR}$ is a POP that contains $75 \mu \mathrm{g}$ desogestrel (DSG). Because DSG, which is rapidly converted to its active metabolite, etonogestrel ${ }^{9,10}$ is more potent than historical POP progestogens and is more selective with regard to androgen receptors, ${ }^{11}$ it can be used at doses sufficient to inhibit ovulation whilst avoiding androgenic effects. Thus, the primary mode of action is ovulation inhibition, and the effects that traditional POPs depend 
upon are secondary for the DSG POP. Increased viscosity of the cervical mucus, as with traditional POPs, provides additional contraceptive protection. The DSG POP has been shown to result in a consistently low Insler score $(<9)$ in the majority of women, 12 which indicates hostility to sperm penetration, as well as having effects on the endometrium that make it unsuitable to support the fertilised ovum. Moreover, while mucus impenetrability is generally considered to be lost approximately 27 hours after dosing, ${ }^{6}$ ovulation inhibition is a more robust mechanism. For the DSG POP, the effects of both ovulation inhibition and cervical mucus impenetrability are considered to provide much longer contraceptive efficacy, allowing a 12-hour pill intake window comparable to that used with COCs. ${ }^{13}$

In order to assess the incidence of ovulation with available COCs and POPs, and to compare this with the ovulation rate reported with the DSG POP, a literature review was performed.

\section{Methods}

A literature search was performed in the following databases: MEDLINE, EMBASE, Biosis, Derwent Drug File, Current Contents and the in-house Organon database 'Docs'. This in-house database consists of all publications extracted from the previously mentioned databases plus the Japanese database JICST, as well as congress abstracts and CD-ROMs. Searches were performed with free-text terms [e.g. Contraceptive $\$$ in combination with (Ovulat\$ adj Rate\$), (Ovar\$ adj Activ\$) or (Escap\$ adj Ovulat\$)] and were limited to the search criteria 'Human' and 'from 1979 onwards'. The searches included publications up to July 2008. Reference lists in publications found via the literature search were also screened for additional publications.

Many of the studies identified in the literature search did not fulfil the criteria for the determination of ovulation as defined by Landgren and Diczfalusy (i.e. progesterone levels of $>16 \mathrm{nmol} / 1$ sustained for at least 5 days $)^{14,15}$ and in many cases no measurements were performed during the most critical days for escape ovulation. The ovulation rates reported in all the studies have been included in Tables 1-4 in order to provide a more complete picture of the data available. However, only data from studies using the strictest criteria for determination of ovulation should be considered as providing accurate information about the incidence of ovulation with the various oral contraceptive methods.

Reported ovulation rates were grouped according to the oral contraceptive method used: COCs containing 30-35 $\mu \mathrm{g}$ ethinylestradiol (EE), COCs containing 15-20 $\mu \mathrm{g}$ EE, phasic COCs, and POPs. The ovulation rate is expressed as the percentage of subjects experiencing ovulation out of the total number of subjects studied; $95 \%$ confidence intervals (CIs) were calculated using exact binomial distribution. ${ }^{16}$

\section{Results}

\section{COCs containing 30-35 $\mu \mathrm{g}$ EE}

Studies employing COCs containing 30-35 $\mu \mathrm{g}$ EE are shown in Table 1, ${ }^{17-37}$ the majority of which reported an absence of ovulation. A total of 16 out of 791 (2.0\%) subjects were found to ovulate. Differences between the various types of $\mathrm{COC}$ were observed, with the ovulation incidence ranging from $1 \%$ to $30 \%$. The upper limits of the $95 \%$ CIs also varied widely between the studies, ranging from $1.7 \%$ to $65.2 \%$. The most widely studied combinations were levonorgestrel (LNG)/EE (273 subjects in 10 studies) with an ovulation incidence of $2.2 \%$ and gestodene (GSD)/EE (277 subjects in four studies) with an ovulation incidence of $0 \%$.
Only four studies used a progesterone level of $>16 \mathrm{nmol} / \mathrm{l}$ as the criterion for ovulation. One of these studies, conducted over six cycles, identified one ovulation amongst 10 users of cyproterone acetate (CPA)/EE 2000/35 $\mu \mathrm{g}$, but none in 10 users of LNG/EE 150/30 $\mu \mathrm{g}, 10$ users of DSG/EE $150 / 30 \mu \mathrm{g}$ or 10 users of norethisterone (NET)/EE 1000/35 $\mu \mathrm{g} .{ }^{18}$ Progesterone levels were measured every 4 days during Cycles 1, 3 and 6. The other three studies all assessed the effects of deliberate omission of pill intake. Landgren and Csemiczky ${ }^{32}$ observed one ovulation in 10 subjects using DSG/EE 150/30 $\mu \mathrm{g}$ after a deliberate extension of the preceding pill-free interval to 10 days. Progesterone levels were measured every other day. No ovulations were reported in 10 women after the omission of $\mathrm{LNG} / \mathrm{EE} 150 / 30 \mu \mathrm{g}$ for the first 2 days of three consecutive cycles. ${ }^{20}$ Progesterone was measured three times weekly during 90 days. Similarly, missing two doses of LNG/EE $150 / 30 \mu \mathrm{g}$ in one cycle did not result in ovulation in 31 women in whom progesterone levels were measured daily. ${ }^{21}$

Amongst the studies that used different progesterone levels to define ovulation, Spona et al. ${ }^{30}$ reported no ovulation (progesterone $>5 \mathrm{nmol} / \mathrm{l}$ ) in 22 women using dienogest (DNG)/EE 2000/30 $\mu \mathrm{g}$, and Elomaa et al..$^{23}$ found no ovulation (progesterone $>9.6 \mathrm{nmol} / \mathrm{l}$ ) among 34 women using GSD/EE 75/30 $\mu \mathrm{g}$. Kuhl et al. ${ }^{33}$ reported one ovulation (progesterone $>9.6 \mathrm{nmol} / \mathrm{l}$ ) among 11 subjects during one observed cycle of DSG/EE 150/30 $\mu \mathrm{g}$ and two ovulations during LNG/EE 150/30 $\mu \mathrm{g}$. Among 85 women who started norgestrel (NG)/EE 300/30 $\mu \mathrm{g}$ on Day 1,4 or 7 of their menstrual cycle, three $(2.4 \%)$ ovulated (progesterone $>9.6 \mathrm{nmol} / \mathrm{l}$ ) during one monitored cycle. ${ }^{36}$ Birtch et al. .37 observed ovulation in one woman out of eight on LNG/EE 150/30 $\mu \mathrm{g}$ for three cycles, using ultrasound evidence of corpus luteum formation as the ovulatory criterion, but the associated hormone levels were extremely low (progesterone $2.5 \mathrm{nmol} / \mathrm{l}$ ).

The remaining studies used a variety of other criteria to assess ovulation. In the largest study $(n=209)^{24}$ ultrasound measurements were scheduled during Days 18-21 of the cycle, which is considered the least critical period with respect to escape ovulation. Despite substantial follicular growth (maximum follicular diameter $>10 \mathrm{~mm}$ in $>10 \%$ of cycles), no ruptured follicles were observed and an absence of escape ovulation was therefore claimed. The fact that a pregnancy occurred illustrates the shortcomings of this ultrasound-only approach. A number of studies either did not assess progesterone levels, ${ }^{26}$ had no predefined definition of ovulation, 19,22,25,29,31 or did not perform measurements during the most critical days for escape ovulation. $17,25,27,28,35$

\section{COCs containing 15-20 $\mu \mathrm{g}$ EE}

Table 2 shows the studies that have been conducted with COCs containing 15-20 $\mu \mathrm{g}$ EE. 17,23,24,26,38-55 Overall, 12 out of $1030(1.1 \%)$ subjects were found to have ovulated. Differences between the various types of COCs were observed, with the ovulation incidence ranging from $0.0 \%$ to $8.6 \%$. The upper limits of the $95 \%$ CIs also varied widely between studies, ranging from $1.7 \%$ to $49.4 \%$. DSG/EE 150/20 $\mu \mathrm{g}$ (507 subjects in 10 studies) and GSD/EE (209 subjects in seven studies) were the most commonly investigated combinations, with ovulation rates of $0.2 \%$ and $0.0 \%$, respectively.

None of the studies used a progesterone level of $>16$ $\mathrm{nmol} / \mathrm{l}$ to define ovulation. One study reported ovulation, using both ultrasound and serum progesterone level $(>5$ $\mathrm{nmol} / \mathrm{l}$ ), in $2 / 25$ subjects during three cycles of $\mathrm{LNG} / \mathrm{EE}$ $100 / 20 \mu \mathrm{g} .{ }^{38}$ Application of the progesterone $>16 \mathrm{nmol} / \mathrm{l}$ 


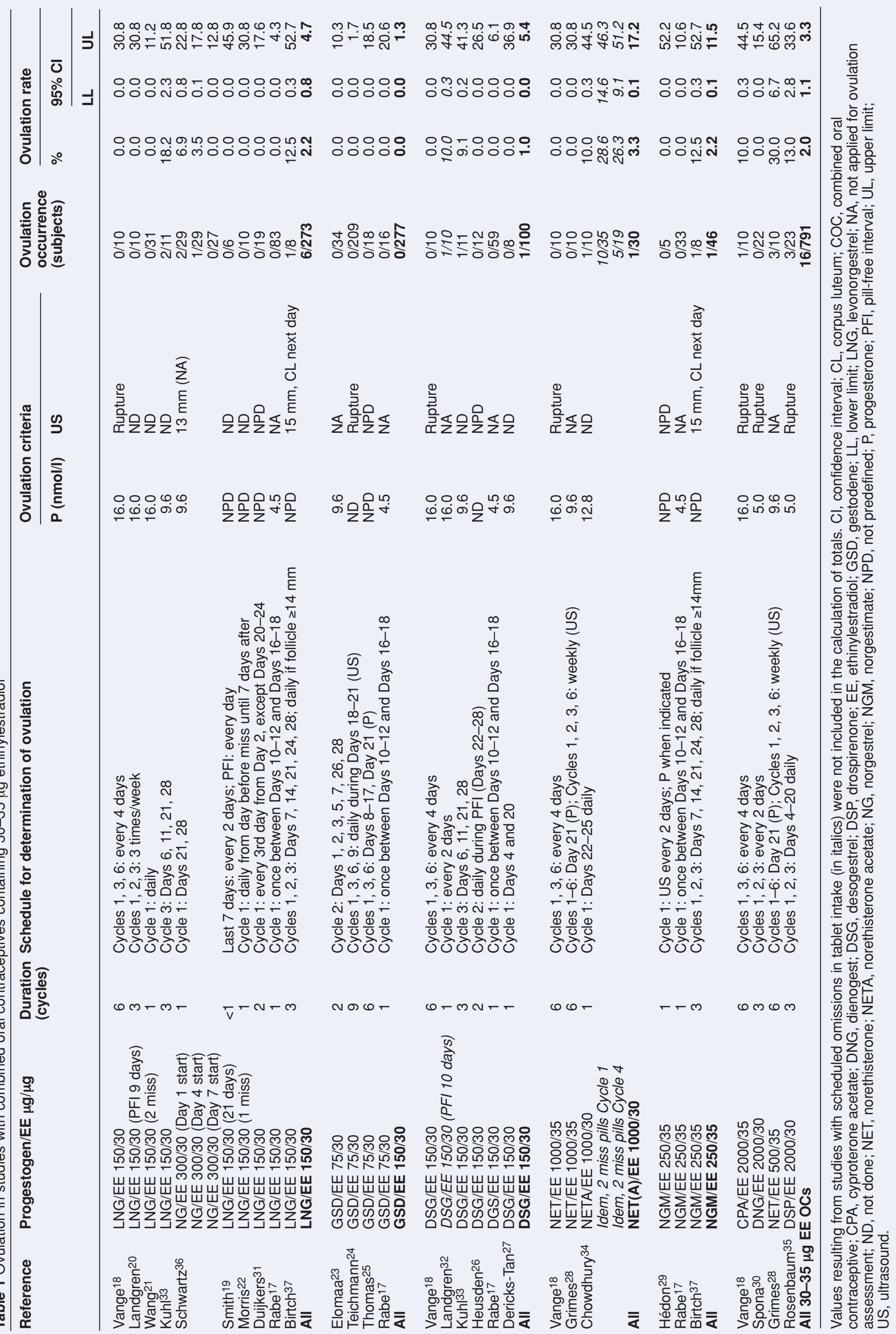




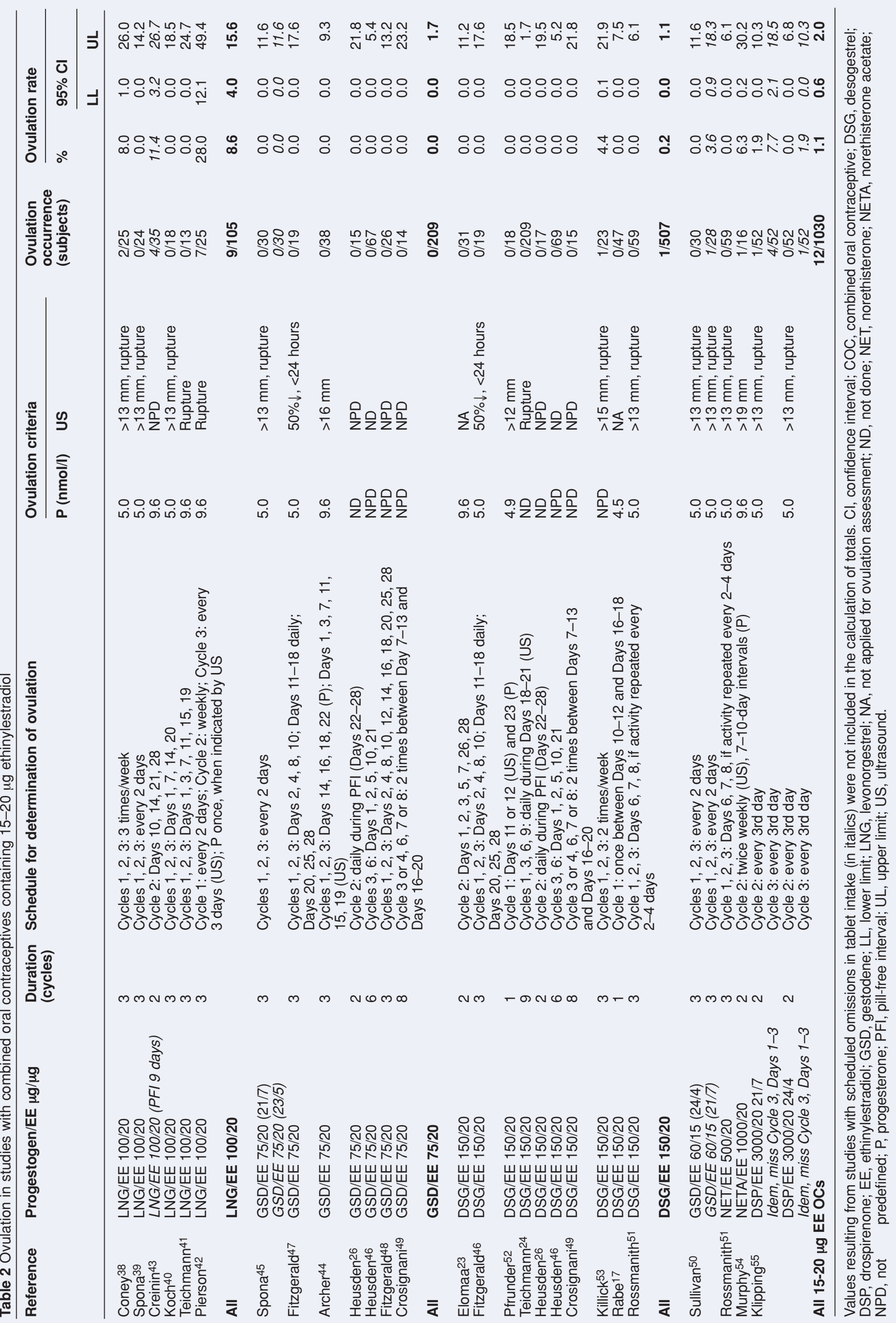




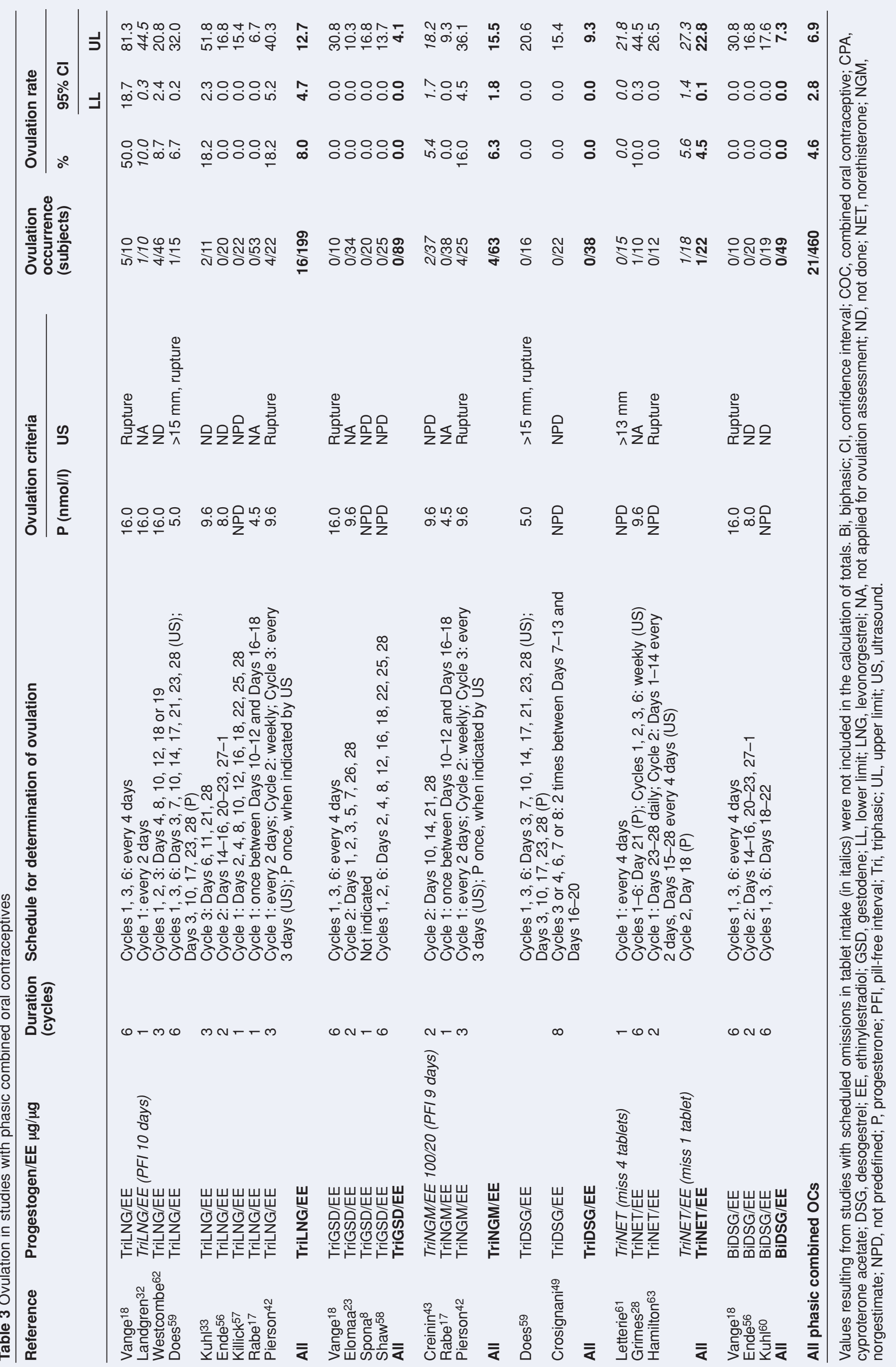


criterion would have resulted in four ovulations out of 25 $(16.0 \%)$ subjects. Another study using the same criteria observed no ovulations amongst 24 subjects over three cycles, although one $(4.2 \%)$ subject had a progesterone level of $>16 \mathrm{nmol} / 1 .{ }^{39}$ Also, in a study in which the first two tablets of Cycle 2 were omitted, 4/35 (11.4\%) subjects ovulated (progesterone $>9.6 \mathrm{nmol} / \mathrm{l}$ ) in that cycle. ${ }^{43} \mathrm{No}$ ovulations were observed in three studies using GSD/EE $75 / 20 \mu \mathrm{g}$ and progesterone levels of $>5 \mathrm{nmol} / \mathrm{l}^{45,47}$ or $>9.6$ $\mathrm{nmol} / 1.44 \mathrm{~A}$ COC containing $60 \mu \mathrm{g}$ GSD and $15 \mu \mathrm{g}$ EE is also available in a regimen of 24 active pills and 4 pill-free days. In a study using an ovulation definition of serum progesterone $>5 \mathrm{nmol} / \mathrm{l}$ combined with follicle diameter of $>13 \mathrm{~mm}$ plus rupture, no ovulations were observed in 30 women treated for three cycles, while one woman out of 28 ovulated using this combination in a 'classical' regimen of 21 active pills and 7 pill-free days. ${ }^{50}$ In the study of Klipping et al..$^{55}$, formulations consisting of drospirenone (DSP) $3 \mathrm{mg}$ and EE $20 \mu \mathrm{g}$ were also investigated in two regimens that differed in the length of the pill-free period. Using the same criteria as the aforementioned study, one woman out of 52 on the 'classical' $21 / 7$ regimen and no one out of 52 on the 24/4 regimen ovulated during Cycle 2. Deliberate omission of the first three pills of the Cycle 3 resulted in four and one woman, respectively, ovulating during Cycle 3 in the 21/7 and 24/4 regimen. Ovulations were not observed in three studies conducted with DSG/EE $150 / 20 \mu \mathrm{g}$ and using progesterone levels of $>9.6 \mathrm{nmol} / 1,{ }^{23}$ $>5 \mathrm{nmol} / \mathrm{l}^{47}$ or $>4.9 \mathrm{nmol} / 1.52$

Finally, several studies did not measure progesterone at all and relied solely on ultrasound 24,26 whilst others did not predefine the progesterone level indicative of ovulation $46,48,49,52$ or did not perform measurements during the critical days for escape ovulation. ${ }^{17,40-42,51,54}$

\section{Phasic COCs}

Table 3 shows the studies performed with triphasic (Tri) or biphasic (Bi) COCs. $8,17,18,23,28,32,33,42,43,49,56-63$ Overall, 21 out of $460(4.6 \%)$ subjects were found to have ovulated. Differences between the various types of COC were observed, with the ovulation incidence ranging from $0.0 \%$ to $8.0 \%$. The upper limits of the $95 \%$ CIs also varied widely between studies, ranging from $6.7 \%$ to $81.3 \%$. The most commonly studied combination was TriLNG/EE (199 subjects in eight studies) with an ovulation incidence of $8.0 \%$.

There were only three studies that used a progesterone level of $>16 \mathrm{nmol} / 1$ as the criterion for ovulation. In the study by van der Vange et al. ${ }^{18}$ in which progesterone was determined every 4 days during Cycles 1,3 and 6 , five out of 10 women ovulated on TriLNG/EE (50\%); these were all well-documented cases associated with high peak progesterone levels (24.1-47.7 nmol/1) and follicular growth and rupture shown by ultrasound. In the same study, no woman ovulated on TriGSD/EE or BiDSG/EE. Another study assessed the effect of missing two doses of TriLNG/EE and reported one ovulation in 10 women; 32 progesterone was measured every 2 days. The third study unfortunately only measured progesterone on Days 4,8 , $10,12,18$ or 19 and therefore levels during the critical days for escape ovulation were not taken into account. ${ }^{62}$ Of the 46 women studied, four $(8.7 \%)$ ovulated.

One possible ovulation among $15(6.7 \%)$ women was reported in a study with TriLNG/EE using ultrasound evidence and progesterone levels of $>5 \mathrm{nmol} / 1 .{ }^{59}$ In the same study, none of 16 women given TriDSG/EE ovulated. Other reports include two ovulations (progesterone $>9.6$ $\mathrm{nmol} / \mathrm{l}$ ) amongst $11(18.2 \%)$ subjects on TriLNG/EE during one monitored cycle. ${ }^{33}$ The deliberate omission of the first two tablets of Cycle 2 resulted in ovulation (progesterone $>9.6 \mathrm{nmol} / \mathrm{l})$ in $2 / 37 \quad(5.4 \%)$ subjects using TriNGM/EE. ${ }^{43}$ Two other studies reported no ovulations with TriGSD/EE (progesterone $>9.6 \mathrm{nmol} / \mathrm{l}$ ) ${ }^{23}$ or BiDSG/EE (progesterone $>8 \mathrm{nmol} / \mathrm{l}) .{ }^{56}$

Although all the studies identified used some measure of progesterone, this was not predefined in several cases $8,49,57,58,60,61,63$ or was not determined in the critical days for escape ovulation in others. ${ }^{17,28,42}$

\section{POPs}

In general, higher ovulation rates are observed in studies with POPs (Table 4), although this does not apply to all formulations. ${ }^{64-69}$ It should be borne in mind, however, that the criteria for determining ovulation were not comparably strict in all studies. There were very marked differences between the traditional POPs (ovulation incidence $42.6 \%$ ) and the DSG POP (ovulation incidence $1.25 \%)$.

\section{Traditional POPs}

Using a strict ovulation criterion of progesterone $>16$ $\mathrm{nmol} / \mathrm{l}$ for at least 5 days, ovulation incidences of $28.6 \%$ (10/35 women) and $39.5 \%$ (17/43 women) have been reported with the $300 \mu \mathrm{g}$ NET POP.12,62 One study measured progesterone levels seven times during Cycle 3,64 whilst the other measured levels daily during one cycle. ${ }^{14}$ High rates of ovulation have also been reported for the $30 \mu \mathrm{g}$ LNG POP, even when the strict criteria of progesterone $>30 \mathrm{nmol} / \mathrm{l}$ combined with a follicle diameter of $>15 \mathrm{~mm}$ plus rupture were applied ( $28.1 \%$ of cycles). ${ }^{66}$ Progesterone levels were determined twice weekly during cycles 7 and 12. A less strict criterion of $>30 \mathrm{nmol} / \mathrm{l}$ progesterone without ultrasound assessment resulted in an ovulation rate of $37.9 \%$. Two further studies relied on ultrasound data only. 65,67

\section{DSG POP}

In contrast to these findings, consistently low levels of ovulation have been observed with $75 \mu \mathrm{g}$ DSG daily.

In the previously cited study, ${ }^{6} 6$ there was one ovulation in 59 cycles $(1.7 \%)$ of $75 \mu \mathrm{g}$ DSG, using a strict definition of progesterone $>30 \mathrm{nmol} / 1$ combined with a follicle diameter of $>15 \mathrm{~mm}$ plus rupture. Progesterone levels indicative of an absence of luteinisation $(<10 \mathrm{nmol} / \mathrm{l})$ were achieved during the first assessed cycle (Cycle 7) in almost all women (97\%) given DSG compared with only $34 \%$ of those given LNG $(p<0.001)$. The percentages of women with progesterone levels $<10 \mathrm{nmol} / \mathrm{l}$ during the second assessed cycle (Cycle 12) were $97 \%$ and $50 \%$, respectively. This was supported by the incidence of follicular rupture that occurred in $6 \%$ and $3 \%$ of women in the DSG group at Cycles 7 and 12, respectively, compared with $31 \%$ and $36 \%$ of the women in the LNG group.

Using an ovulation criterion of progesterone $>16 \mathrm{nmol} / \mathrm{l}$ plus a follicle diameter of $>15 \mathrm{~mm}$ plus rupture, Obruca $e t$ al. ${ }^{68}$ reported no ovulations amongst 13 women using 75 $\mu \mathrm{g}$ DSG. Progesterone levels were measured daily during one cycle. Two further studies, which used the less strict criterion of progesterone $>10 \mathrm{nmol} / 1$, reported no ovulations in 14 women ${ }^{11}$ and 23 women, ${ }^{69}$ respectively.

Considering the narrow timing of the dosing window afforded by most POPs, the effects of a 12-hour delay in tablet intake were investigated with $75 \mu \mathrm{g}$ DSG. ${ }^{13}$ Of 103 women who received DSG for two cycles and who were scheduled to take their tablets 12 hours late on Days 11,14 and 21 of either the first or second cycle, only one $(1 \%)$ woman was found to ovulate according to the strict criterion of progesterone $>16 \mathrm{nmol} / 1$ for 5 days. 


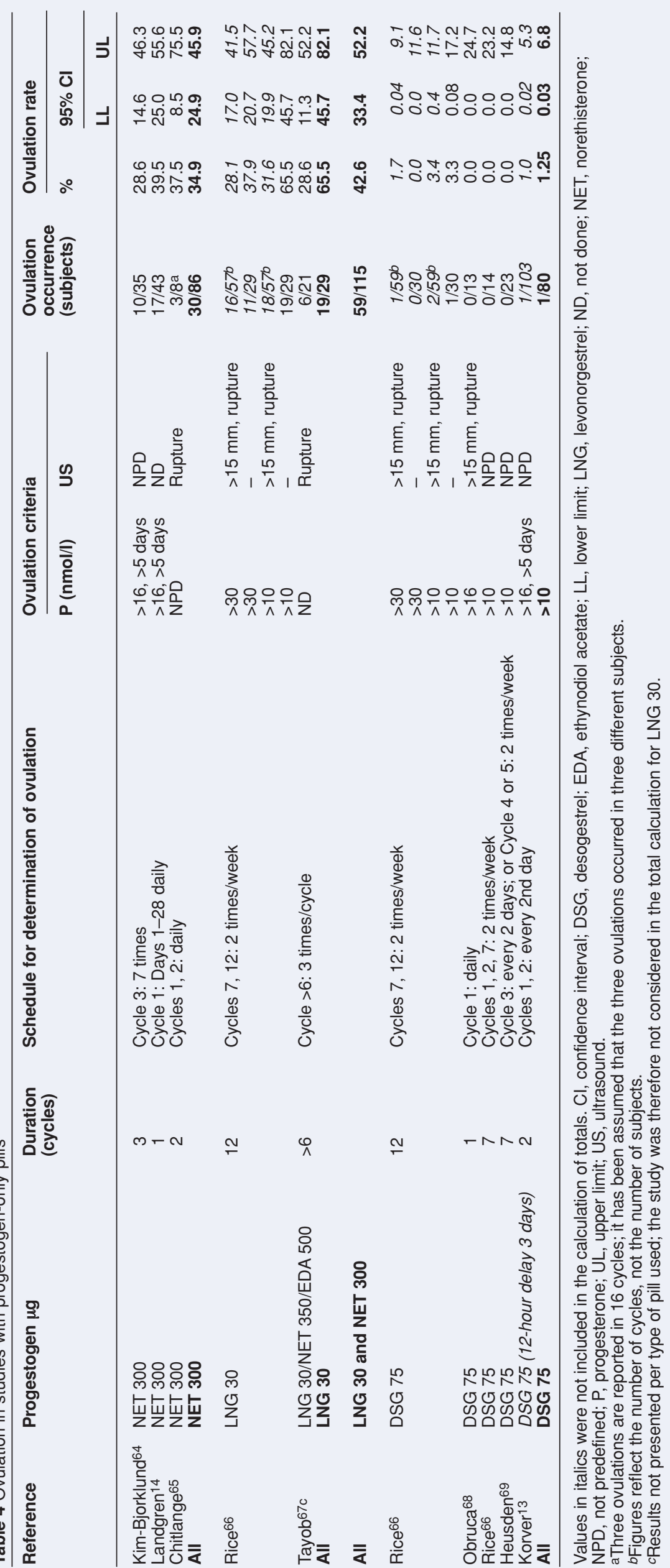


Progesterone was measured every second day over two cycles. Return of ovulation took at least 7 days after DSG was stopped, although all women had ovulated within 30 days.

\section{Discussion}

The overall incidence of ovulation determined by this literature search was $2.0 \%$ with 30-35 $\mu \mathrm{g}$ EE COCs, $1.1 \%$ with 15-20 $\mu \mathrm{g}$ EE COCs, $4.6 \%$ with phasic COCs, $1.25 \%$ with the DSG POP and $42.6 \%$ with traditional POPs. Although some of the progestogens used in the 30-35 $\mu \mathrm{g}$ EE COCs appeared to be associated with somewhat higher rates of ovulation (e.g. NET, DSP and CPA), this may have been due to the small number of studies conducted with these formulations. In contrast, the ovulation rate with 15-20 $\mu \mathrm{g}$ EE COCs was notably higher with preparations containing the progestogen LNG; the overall incidence of ovulation was $8.6 \%(9 / 105)$ in a total of five studies. This incidence would have been further increased if the more accurate criterion of progesterone levels $>16 \mathrm{nmol} / \mathrm{l}$ was applied to the studies for which it was available.39,40,42 Ovulation rates with the various types of phasic COCs were also highest with TriLNG/EE, with an incidence of $16 / 199(8.0 \%)$ in a total of eight studies. However, the greatest difference between the progestogens was observed with the POPs. The highest ovulation rates amongst all the oral contraceptives were seen with $300 \mu \mathrm{g}$ NET POPs [30/86 (34.9\%) subjects in three studies] and $30 \mu \mathrm{g}$ LNG POPs [19/29 $(65.5 \%)$ subjects in one study]. The $75 \mu \mathrm{g}$ DSG POP Cerazette was a notable exception, with just one woman out of $80(1.3 \%)$ ovulating in four studies, which is comparable to COCs.

Adequately timed and frequent sampling of serum for determination of progesterone levels is considered a prerequisite for detecting ovulation. Many of the studies cited in this literature review do not fulfil this criterion. In particular, the largest study, ${ }^{24}$ which included 207 subjects on DSG/EE 150/20 $\mu \mathrm{g}$ and 209 on GSD/EE 75/30 $\mu \mathrm{g}$, did not measure progesterone levels. In addition, the frequency and timing of ultrasound scans (four scans during the least critical period for escape ovulation) were insufficient to draw conclusions, as illustrated by the fact that a pregnancy occurred despite the reported absence of ovulation. It should also be noted that interpretation of an ultrasound can be ambiguous. Even in a physiological menstrual cycle, the wide range of pre-ovulatory follicle sizes and the varying ultrasonic appearance of the corpora lutea preclude the use of follicular diameter as the sole criterion for ovulation. The situation is even more complex in women taking steroid contraception due to disturbed folliculogenesis and the presence of multiple follicles. ${ }^{70}$ Serum progesterone levels appear to be a more robust parameter in view of the steep rise observed after ovulation. Regular blood sampling during the menstrual cycle of normally menstruating women revealed that postovulatory maximum progesterone levels were considerably greater than $16 \mathrm{nmol} / 1$ in all women and that these levels were maintained for at least 5 days in $95 \%$ of women. ${ }^{14,15}$ Progesterone levels of $>16 \mathrm{nmol} / 1$ sustained for at least 5 days would therefore appear to be a good indicator of ovulation. The timing of measurements is also important; with COCs the risk of escape ovulation increases with each day of the routinely scheduled pillfree-interval (usually Days 22-28), reaching its peak during the first few days after tablet intake is resumed. ${ }^{71}$ It therefore appears that both frequent and adequately timed sampling of serum progesterone is a prerequisite for detecting ovulation.

Unfortunately, many of the studies that used adequate criteria for ovulation only included a small number of subjects. Moreover, interpretation of the data is hampered by methodological differences between the studies, in particular the definition of ovulation, the frequency and timing of measurements, the duration of study, and the bioanalytical and statistical methods, as well as by a lack of detail in the publications. In addition, the possibility of selective publication cannot be ruled out.

In general, however, the data show that COCs, as well as the desogestrel POP, are effective in suppressing ovulation, whilst the traditional POP formulations are not as reliable. Nevertheless, the ovulation suppression with COCs is not complete; monophasic COCs containing 15-20 $\mu \mathrm{g}$ EE or 30-35 $\mu \mathrm{g}$ EE show overall incidences of $1.0 \%$ and $2.0 \%$, respectively, with phasic COCs appearing a little less effective with an overall incidence of $4.6 \%$. Some formulations within these categories show substantially higher incidences, but whether this reflects a true difference in potency or just a difference in study design is difficult to determine. The findings with traditional POPs in general confirm that these contraceptives do not primarily rely on ovulation inhibition as the mechanism of action, with an overall ovulation incidence of $42.6 \%$. The DSG POP is different in this respect, with an overall ovulation incidence of $1.25 \%$, comparable to that achieved with the COCs.

It is difficult to extrapolate for each formulation the observed differences in ovulation inhibition to actual contraceptive failure rates. From published clinical trial failure data it is often not clear on the basis of which criteria subjects were selected, which (sub-)population was used for the analysis (e.g. evaluable subjects, intentto-treat or per protocol dataset) and whether subjects not at risk were excluded from the overall exposure. In addition, failure rates may be expressed as 'method', 'user' or overall failure rate, but the criteria applied to make these distinctions are not always clear; besides, failure rates may be differently expressed, either as Pearl indices or as Life Table rates (with either 6-month, 1-year or 2-year rates presented). Variation also exists between studies in the number of subjects studied and the study duration, both of which may significantly impact reported Pearl indices. Also, the level of control exerted during a study may have a major impact on subject compliance and failure, but can often not be deduced from publications. Notwithstanding these limitations, the general trend that emerges from published clinical trial failure rates is consistent with that of the ovulation rates reported here. That is, published failure rates (Pearl indices) range from 0.0 to 1.55 for monophasic OCs containing either $30 \mu \mathrm{g}$ or $20 \mu \mathrm{g} \mathrm{EE}$, from 0.25 to 4.4 for triphasic pills and from 0.5 to 13.0 for (traditional) POPs. Surveys from abortion registries constitute another possible source of information on determinants of contraceptive failure. Some surveys have attempted to distinguish between the types of pills used around the time of unintended pregnancy. A survey conducted in The Netherlands 72 revealed a significantly increased proportion of sequential and phasic pill users among pill failures than in the general population, while also the proportion of traditional POP users among failures was higher than predicted from their market share. In a New Zealand survey, ${ }^{73}$ it was observed that most COCs failed as expected from their respective market shares, but this time no difference was apparent between monophasic and phasic COCs. Conversely, POP users were overrepresented among failures, accounting for $18.4 \%$ of failures at a market share of $11.0 \%$.

The traditional POP options available to date are 
limited by their reduced efficacy, their requirement for strict adherence to the dosing schedule, and the occurrence of irregular vaginal bleeding; they are therefore generally recommended mainly for older women and those who are breastfeeding.

The potentially greater efficacy of the DSG POP compared with traditional POPs has been confirmed in a large double-blind, randomised, multicentre study. ${ }^{74} \mathrm{~A}$ total of 1320 healthy women received either the DSG POP $(n=989)$ or LNG $30 \mu \mathrm{g} /$ day $(n=331)$ for 13 consecutive treatment periods of 28 days. The total exposure was 728 woman-years to the DSG POP and 258 woman-years to LNG. The proportion of women who were starting contraception for the first time (starters), who were switching from another form of contraception (switchers) or who were breastfeeding at the start of the study was similar and was comparable in the two groups. Overall, there were three pregnancies in the DSG POP group and four in the LNG group, resulting in Pearl indices (number of pregnancies per 100 women-years) of 0.41 and 1.55, respectively. Two pregnancies in the DSG POP pill group and one in the LNG group could be attributed to gross noncompliance (tablets deliberately stopped, missed for several days or taken irregularly), resulting in one pregnancy during the DSG POP use and three during LNG use, resulting in 'perfect use' Pearl indices of 0.14 and 1.17, respectively.

Good compliance is essential to maintain contraceptive efficacy. This is somewhat easier to achieve with the DSG POP than with traditional POPs due to its greater flexibility. As the effect of traditional POPs on cervical mucus is maintained for only about 27 hours, the pills must be taken within a strict 3-hour window each day. Because such mucosal changes are less important as a mechanism of contraception with the desogestrel POP, which relies mainly on inhibition of ovulation, a delay in pill intake of up to 12 hours will not affect its efficacy. ${ }^{13}$

In conclusion, although some of the studies are hampered by inadequate ovulation criteria, the literature search indicates that the DSG POP and the (monophasic) COCs share the ability to consistently inhibit ovulation. Thus, the DSG POP pill provides an alternative that is equally effective in preventing ovulation as COCs for women who need to avoid exogenous estrogen exposure.

\section{Statements on funding and competing interests}

Funding lan Milsom has received research funding from Organon. Competing interests Tjeerd Korver is an employee of ScheringPlough (formerly Organon), manufacturer of contraceptives including Cerazette ${ }^{\circledR}$.

\section{References}

1 Dawson DA. Trends in use of oral contraceptives. Data from the 1987 National Health Interview Survey. Fam Plann Perspect 1990; 22: 169-172.

2 Oddens B, Milsom I. Contraceptive practice and attitudes in Sweden 1994. Acta Obstet Gynecol Scand 1996; 75: 932-940.

3 Dawe F, Rainford L. Contraception and Sexual Health, 2003. London, UK: Office for National Statistics, 2003. http://www.statistics.gov.uk/downloads/theme health/ Contraception2003.pdf [Accessed 15 March 2008].

4 Milsom I. Longitudinal studies of birth control and pregnancy outcome among women in an urban Swedish population. In: Glasier A, Wellings K, Critchley $\mathrm{H}$ (eds), Contraception and Contraceptive Use. London, UK: RCOG Press, 2005.

5 Kelsey JJ. Hormonal contraception and lactation. J Hum Lact 1996; 12: 315-318.

6 McCann MF, Potter LS. Progestin-only oral contraception: a comprehensive review. Contraception 1994; 50(Suppl. 1): 9-195.

7 Kesserü-Koos E. Influence of various hormonal contraceptives on sperm migration in vivo. Fertil Steril 1971; 22: 584-603.

8 Spona J, Lachnit-Fixson U, Düsterberg B, Dobianer K Inhibition of ovulation by a triphasic gestodene-containing oral contraceptive. Adv Contracept 1993; 9: 187-194.

9 Viinikka L, Ylikorkala O, Vihko R, Hasenack HG, Nieuwenhuyse $\mathrm{H}$. Metabolism of a new synthetic progestogen, Org 2969, in female volunteers. The distribution and excretion of radioactivity after an oral dose of the labeled drug. Acta Endocrinol 1980; 93: 375-379.

10 Viinikka L, Ylikorkala O, Vihko R, Wijnand HP, Booij M, van der Veen F. Metabolism of a new synthetic progestogen, Org 2969, in female volunteers. Investigations into the pharmacokinetics after an oral dose. Eur J Clin Pharmacol 1979; 15: 349-355.

11 Kloosterboer HJ, Vonk-Noordegraaf CA, Turpijn EW. Selectivity in progesterone and androgen receptor binding of progestogens used in oral contraceptives. Contraception 1988; 38: 325-332.

12 Rice C, Killick S, Hickling D, Coelingh Bennink H. Ovarian activity and vaginal bleeding patterns with a desogestrel-only preparation at three different doses. Hum Reprod 1996; 11: 737-740.

13 Korver T, Klipping C, Heger-Mahn D, Duijkers I, van Osta G, Dieben T. Maintenance of ovulation inhibition with the $75 \mu \mathrm{g}$ desogestrel-only contraceptive pill (Cerazette) after scheduled 12-hour delays in tablet intake. Contraception 2005; 71: 8-13.

14 Landgren B, Diczfalusy E. Hormonal effects of the $300 \mathrm{mg}$ Norethisterone (NET) minipill. 1. Daily steroid levels in 43 subjects during a pretreatment cycle and during the second month of NET administration. Contraception 1980; 21: 87-113.

15 Landgren B-M, Undén A-L, Diczfalusy E. Hormonal profile in the cycle of 68 normally menstruating women. Acta Endocrinol 1980; 94: 89-96.

16 Clopper CJ, Pearson ES. The use of confidence or fiducial limits illustrated in the case of the binomial. Biometrika 1934; 26: 404-413.

17 Rabe T, Nitsche DC, Runnebaum B. The effects of monophasic and triphasic oral contraceptives on ovarian function and endometrial thickness. Eur J Contracept Reprod Health Care 1997; 2: 39-51.

18 van der Vange N. Ovarian activity during low dose oral contraceptives. In: Chamberlain G (ed.), Contemporary Obstetrics and Gynaecology. London, UK: Butterworth, 1988; 315-326.

19 Smith SK, Kirkman RJE, Arce BB, McNeilly AS, Loudon NB, Baird DT. The effect of deliberate omission of Trinordiol or Microgynon on the hypothalamo-pituitary-ovarian axis. Contraception 1986; 34: 513-522.

20 Landgren B-M, Diczfalusy E. Hormonal consequences of missing the pill during the first two days of three consecutive artificial cycles. Contraception 1984; 29: 437-446.

21 Wang E, Shi S, Cekan SZ, Landgren B-M, Diczfalusy E. Hormonal consequences of "missing the pill". Contraception 1982; 26: 545-566.

22 Morris SE, Groom GV, Cameron ED, Buckingham MS, Everitt JM, Elstein M. Studies on low dose oral contraceptives: plasma hormone changes in relation to deliberate pill ('Microgynon 30') omission. Contraception 1979; 20: 61-69.

23 Elomaa K, Rolland R, Brosens I, Moorrees M, Deprest J, Tuominen J, et al. Omitting the first oral contraceptive pills does not automatically lead to ovulation. Am J Obstet Gynecol 1998; 179: $41-46$

24 Teichmann AT, Brill K, Albring M, Schnitker J, Woitynek P, Kustra $\mathrm{E}$. The influence of the dose of ethinylestradiol in oral contraceptives on follicle growth. Gynecol Endocrinol 1995; 9: 299-305.

25 Thomas K, Vankrieken L. Inhibition of ovulation by a low-dose contraceptive containing gestodene. Int J Fertil 1989; 34(Suppl.): 10-21.

26 van Heusden AM, Fauser BJCM. Activity of the pituitaryovarian axis in the pill-free interval during use of low dose combined oral contraceptives. Contraception 1999; 59: 237-243.

27 Dericks-Tan JSE, Gudacker V, Taubert HD. Influence of oral contraceptives on integrated secretion of gonadotropins. Contraception 1992; 46: 369-377.

28 Grimes DA, Godwin AJ, Rubin A, Smith JA, Lacarra M. Ovulation and follicular development associated with three lowdose oral contraceptives: a randomized controlled trial. Obstet Gynecol 1994; 83: 29-34.

29 Hédon B, Cristol P, Plauchut A, Vallon AM, Desachampts F, Taillant $\mathrm{M}$, et al. Ovarian consequences of the transient interruption of combined oral contraceptives. Int J Fertil 1992; 37: $270-276$

30 Spona J, Feichtinger W, Kindermann C, Moore C, Mellinger U, Walter $\mathrm{F}$, et al. Modulation of ovarian function by an oral contraceptive containing $30 \mathrm{\mu g}$ ethinyl estradiol in combination with 2.00 mg dienogest. Contraception 1997; 56: 185-191. 
31 Duijkers IJM, Klipping C, Verhoeven CHJ, Dieben TOM. Ovarian function with the contraceptive vaginal ring or an ora contraceptive: a randomized study. Hum Reprod 2004; 19: 2668-2673.

32 Landgren BM, Csemiczky G. The effect on follicular growth and luteal function of "missing the pill". A comparison between a monophasic and a triphasic combined oral contraceptive. Contraception 1991; 43: 149-159.

33 Kuhl H, Gahn G, Romberg G, Maerz W, Taubert HD. A randomized cross-over comparison of two low-dose oral contraceptives upon hormonal and metabolic parameters: Effects upon sexual hormone levels. Contraception 1985; 31: 583-593.

34 Chowdhury V, Joshi UM, Gopalkrishna K, Betrabet S, Mehta S, Saxena BN. 'Escape' ovulation in women due to the missing of low dose combination oral contraceptive pills. Contraception 1980; 22: 241-248.

35 Rosenbaum P, Schmidt W, Helmerhorst FM, Wuttke W, Rossmanith W, Freundl F, et al. Inhibition of ovulation by a novel progestogen (drospirenone) alone or in combination with ethinylestradiol. Eur J Contracept Reprod Health Care 2000; 5 : 16-24.

36 Schwartz JL, Creinin MD, Pymar HC, Reid L. Predicting risk of ovulation in new start oral contraceptive users. Obstet Gynecol 2002; 99: 177-182.

37 Birtch RL, Olatunbosun OA, Pierson A. Ovarian follicular dynamics during conventional vs. continuous oral contraceptive use. Contraception 2006; 73: 235-243.

38 Coney $\mathrm{P}$, DelConte $\mathrm{A}$. The effects on ovarian activity of a monophasic contraceptive with $100 \mu \mathrm{g}$ levonorgestrel and 20 ug ethinylestradiol. Am J Obstet Gynecol 1999; 181: S53-S58.

39 Spona J, Feichtinger W, Kindermann Ch, Wünsch C, Brill K. Inhibition of ovulation by an oral contraceptive containing 100 $\mu \mathrm{g}$ levonorgestrel in combination with $20 \mu \mathrm{g}$ ethinylestradiol. Contraception 1996; 54: 299-304.

40 Koch K, Campanella C, Baidoo CA, Manzo JA, Ameen VZ, Kersey KEE. Pharmacodynamics and pharmacokinetics of oral contraceptives co-administered with alosetron (Lotronex). Dig Dis Sci 2004; 49: 1244-1249.

41 Teichmann A, Martens H, Bordasch C, Petersen G, Lorkowski $G$. The effects of a new low-dose combined oral contraceptive containing levonorgestrel on ovarian activity. Eur J Contracept Reprod Health Care 1996; 1: 245-256.

42 Pierson RA, Archer DA, Moreau M, Shangold GA, Fisher AC, Creasy GW. Ortho Evra/Evra versus oral contraceptives: follicular development and ovulation in normal cycles and after an intentional dosing error. Fertil Steril 2003; 80: 34-42.

43 Creinin MD, Lippman JS, Eder SE, Godwin AJ, Olson W. The effect of extending the pill-free interval on follicular activity: triphasic norgestimate/35 $\mu \mathrm{g}$ ethinylestradio versus monophasic levonorgestrel/20 $\mathrm{ug}$ ethinylestradiol. Contraception 2002; 66: 147-152.

44 Archer D, Gast MJ. An investigation of ovulation inhibition with a low-dose combined oral contraceptive containing $75 \mathrm{ug}$ gestodene and $20 \mu \mathrm{g}$ ethinylestradiol. Gynecol Endocrinol 1998; 12(Suppl. 4): 7-12.

45 Spona J, Elstein M, Feichtinger W, Sullivan H, Lüdicke F, Mülle $\mathrm{U}$, et al. Shorter pill-free interval in combined ora contraceptives decreases follicular development. Contraception 1996; 54: 71-77.

46 van Heusden AM, Fauser BJCM, Spielmann D. A comparative clinical investigation of endocrine parameters with two low dose oral contraceptives containing either $75 \mathrm{\mu g}$ gestodene or $150 \mu \mathrm{g}$ desogestrel combined with $20 \mu \mathrm{g}$ ethinylestradiol. Gynecol Endocrinol 1998; 12(Suppl. 4): 13-19.

47 Fitzgerald C, Feichtinger W, Spona J, Elstein M, Lüdicke F, Müller U, et al. A comparison of the effects of two monophasic low dose oral contraceptives on the inhibition of ovulation. Adv Contracept 1994; 10: 5-18.

48 Fitzgerald C, Elstein M, Spona J. Effect of age on the response of the hypothalamo-pituitary-ovarian axis to a combined oral contraceptive. Fertil Steril 1999; 71: 1079-1084.

49 Crosignani PG, Testa G, Vegetti W, Parazzini F. Ovarian activity during regular oral contraceptive use. Contraception 1996; 54: 271-273.

50 Sullivan $\mathrm{H}$, Furniss $\mathrm{H}$, Spona J, Elstein M. Effect of 21-day and 24-day oral contraceptive regimens containing gestodene (60 $\mu \mathrm{g})$ and ethinylestradiol (15 $\mu \mathrm{g})$ on ovarian activity. Fertil Steril 1999; 72: 115-120.

51 Rossmanith WG, Steffens D, Schramm G. A comparative randomized trial on the impact of two low-dose oral contraceptives on ovarian activity, cervical permeability and endometrial receptivity. Contraception 1997; 56: 23-30.

52 Pfrunder A, Schiesser M, Gerber S, Haschke M, Bitzer J,
Drewe J. Interaction of St John's wort with low-dose oral contraceptive therapy: a randomized controlled trial. $\mathrm{Br} J$ Clin Pharmacol 2003; 56: 683-690.

53 Killick SR, Fitzgerald C, Davis A. Ovarian activity in women taking an oral contraceptive containing 20 microg ethinyl estradiol and 150 microg desogestrel: effects of low estrogen doses during the hormone-free interval. Am J Obstet Gynecol 1998; 179: S18-S24.

54 Murphy PA, Kern SE, Stanczyk FZ, Westhoff CL. Interaction of St John's wort with oral contraceptives: effects on the pharmacokinetics of norethindrone and ethinyl estradiol, ovarian activity and breakthrough bleeding. Contraception 2005; 71: 402-408.

55 Klipping C, Duijkers I, Trummer D, Marr J. Suppression of ovarian activity with a drospirenone-containing ora contraceptive in a 24/4 regimen. Contraception 2008; 78 16-25.

56 van den Ende A, Geurts TBP, Kloosterboer HJ. A randomized cross-over study comparing pharmacodynamic and metabolic variables of a new combiphasic and a well-established triphasic oral contraceptive. Eur J Contracept Reprod Health Care 1997; 2: 173-180.

57 Killick S, Eyong E, Elstein M. Ovarian follicular development in oral contraceptive cycles. Fertil Steril 1987; 48: 409-413.

58 Shaw G, Killick S, Elstein M. Assessment of ovarian activity in a gestodene-containing triphasic oral contraceptive. $\mathrm{Br} J$ Fam Plann 1992; 18: 72-78.

59 van der Does J, Exalto $\mathrm{N}$, Dieben T, Coelingh Bennink H. Ovarian activity suppression by two different low-dose triphasic oral contraceptives. Contraception 1995; 52: 357-361.

60 Kuhl H, Jung-Hoffmann C, Weber J, Boehm BO. The effect of a biphasic desogestrel-containing oral contraceptive on carbohydrate metabolism and various hormonal parameters. Contraception 1993; 47: 55-68.

61 Letterie GS, Chow GE. Effect of "missed" pills on ora contraceptive effectiveness. Obstet Gynecol 1992; 79 979-982.

62 Westcombe R, Ellis R, Fotherby K. Suppression of ovulation in women using a triphasic oral contraceptive. $\mathrm{Br} J$ Fam Plan 1987; 13: 127-132.

63 Hamilton CJC, Hoogland HJ. Longitudinal ultrasonographic study of the ovarian suppressive activity of a low-dose triphasic oral contraceptive during correct and incorrect pill intake. $A m \mathrm{~J}$ Obstet Gynecol 1989; 161: 1159-1162.

64 Kim-Björklund T, Landgren BM, Johanisson E. Morphometric studies of the endometrium, fallopian tube and the corpus luteum during contraception with the $300 \mathrm{ug}$ norethisterone (NET) minipill. Contraception 1991; 43: 459-474.

65 Chitlange SM, Shah RS, Hazari KT, Anandkumar TC, Puri CP. Ultrasonographic monitoring of ovarian follicles in women using norethisterone for contraception. Int J Gynecol Obstet 1996; 53: 31-34.

66 Rice CF, Killick SR, Dieben T, Coelingh Bennink H. A comparison of the inhibition of ovulation achieved by desogestrel $75 \mu \mathrm{g}$ and levonorgestrel $30 \mu \mathrm{g}$ daily. Hum Reprod 1999; 14: 982-985.

67 Tayob Y, Adams J, Jacobs HS, Guillebaud J. Ultrasound demonstration of increased frequency of functional ovarian cysts in women using progestogen-only contraception. $\mathrm{Br} J$ Obstet Gynaecol 1985; 92: 1003-1009.

68 Obruca A, Korver T, Huber J, Killick SR, Landgren BM, Struijs MJ. Ovarian function during and after treatment with the new progestogen Org 30659. Fertil Steril 2001; 76: 108-115.

69 van Heusden AM, Killick SR, Coelingh Bennink HJT, Fauser BJCM. Single monthly administration of the anti-progestagen Org 31710 in users of the 75 microg desogestrel progestagenonly pill: effects on pituitary-ovarian activity. Hum Reprod 2000; 15: 629-636.

70 Queenan JT, O'Brien GD, Bains LM, Simpson J, Collins WP Campbell S. Ultrasound scanning of ovaries to detect ovulation in women. Fertil Steril 1980; 34: 99-105

71 Korver T, Goorissen E, Guillebaud J. The combined contraceptive pill: what advice should we give when tablets are missed? Br J Obstet Gynaecol 1995; 102: 601-607.

72 Ketting $E$. The relative reliability of oral contraceptives: findings of an epidemiological study. Contraception 1988; 37: 343-348.

73 Sparrow MJ. Pill method failures in women seeking abortion: fourteen years experience. N Z Med J 1998; 111: 386-388.

74 Collaborative Study Group on the Desogestrel-containing Progestogen-only Pill. A double-blind study comparing the contraceptive efficacy, acceptability and safety of two progestogen-only pills containing desogestrel $75 \mathrm{ug} /$ day or levonorgestrel $30 \mu \mathrm{g} / \mathrm{day}$. Eur J Contracept Reprod Health Care 1998; 3: 169-178. 